\title{
OS FATORES ECONÔMICOS E A TECNOLOGIA NO DESEMPREGO ESTRUTURAL
}

\author{
Wallace Leite Nogueira ${ }^{1}$ \\ Victor Hugo Tejerina Velázquez ${ }^{2}$
}

\section{RESUMO}

O presente artigo analisa os fatores econômicos após a Segunda Guerra Mundial e utilização de tecnologia no trabalho e suas implicações no mercado de trabalho. Os fatos econômicos históricos globais justificam o desenvolvimento tecnológico como forma de viabilizar ao máximo os lucros e reduzir drasticamente os custos. Esta análise será jurídica e sociológica da posição do trabalhador no mundo contemporâneo frente aos meios tecnológicos bem como a análise da norma protetiva constitucional do trabalhador insculpida no artigo $7^{\circ}$, XXVII da Constituição e sua efetividade.

Palavras-chave: Tecnologia e automação; Direito Fundamental ao Trabalho; Desemprego tecnológico.

\section{THE ECONOMIC FACTORS AND THE TECHNOLOGY IN STRUCTURAL UNEMPLOYMENT}

\begin{abstract}
This article analyzes the economic factors after the Second World War and the use of technology at work and its implications in the labor market. The global historical economic facts justify the technological development as a way to make the profits feasible to the maximum and drastically reduce the costs. This analysis will be juridical and sociological of the position of the worker in the contemporary world in front of the technological means as well as the analysis will be made of the constitutional protective norm of the worker inscribed in article 7, XXVII of the Constitution and its effectiveness.
\end{abstract}

Keywords: Technology and automation; Technological unemployment; Fundamental Right to Work.

\section{INTRODUÇÃO}

As tecnologias são desenvolvidas cada vez mais rápido e passa fazer parte do dia a dia das pessoas que, muitas vezes nem se dão conta dos malefícios que estas podem

\footnotetext{
${ }^{1}$ Mestre em direito pela Universidade Metodista de Piracicaba. Especialista e Direito Empresarial pela Fundação Getúlio Vargas. Atuação, como advogado, na área de direito empresarial e professor de Direito na Faculdade de Americana.

${ }^{2}$ Advogado. Mestre e Doutor em Direito pela Pontifícia Universidade Católica de São Paulo. Idealizador e fundador de Cadernos de Direito e da Revista Discente Interinstitucional. Professor, Fundador e ex-Coordenador do Programa de Pós-Graduação em Direito da UNIMEP. Coordenador do NEDAEPI.
} 
ocasionar. Evidente que as tecnologias mostram ostensivamente suas comodidades, mas acabam por ocultar efeitos perniciosos que podem causar a médio e longo prazo na sociedade.

A máquina a vapor representa a maquinização iniciada na Revolução Industrial e trouxe uma série de consequências sociais, como a migração em massa e a exploração do trabalhador, sem que houvesse uma proteção efetiva.

A aplicação de novas técnicas e tecnologia objetivam atingir o máximo de eficiência e, assim, aumentar o lucro e reduzir ao máximo os custos. Estas técnicas e tecnologias foram e são utilizadas em diversos setores da economia, como metalúrgico, bancário, etc.

O direito ao trabalho é um direito fundamental que deve ser preservado como forma de garantir a dignidade da pessoa humana, razão pela qual o direito do acesso ao trabalho deve ser preservado pelo Estado.

O artigo conta com estudos realizados através de pesquisas bibliográficas e documentais visando analisar a utilização de meios tecnológicos e da automação nos postos de trabalho, bem como os dispositivos legais em vigor onde foi adotada a metodologia de análise das pesquisas bibliográficas, legislativas, e jurisprudencial através do método dialético, aplicando-se o método hipotético-dedutivo uma vez que a doutrina conta com pouca análise do tema, e a exposição foi feita na forma narrativa.

A linha de pesquisa utilizada para este estudo foi crítico metodológica onde se buscou a análise do aspecto jurídico do direito de proteção do trabalhador a que se refere o artigo $7^{\circ}$, inciso XXVII da Constituição Federal, bem como levantamento bibliográfico sobre a problemática do tema e foi adotada a vertente jurídico sociológica para o desenvolvimento do tema.

DESENVOLVIMENTO 
O termos "tecnologia" (do grego technología, que significa tratado sobre uma arte), pode ser entendido como um conjunto de conhecimentos, princípios científicos que se aplicam a um determinado ramo de atividade (FERREIRA, 2010, p. 2015). No espectro jurídico as autoras Baumgarten e Holzmann explicitam:

Tecnologia pode ser definida, genericamente como a atividade socialmente organizada, baseada em planos e de caráter essencialmente prático. Compreende, portanto, conjuntos de conhecimentos e informações utilizadas na produção de bens e serviços, provenientes de fontes diversas, como descobertas científicas e invenções, obtidas por meio de distintos métodos, a partir de objetivos definidos e com finalidades práticas (2011, p. 391-392).

Alguns autores preferem a utilização da terminologia "técnica" a tecnologia, como Jacques Ellul e justifica que esta é apenas a atividade inventiva igenua, enquanto aquela designa um sentido de produção, um fazer eficaz (1968, p. 19-20).

Ainda que não haja unanimidade no que tange aos conceitos, é certo que houve na história mundial um fato de relevante importância na Revolução Industrial: o "maquinismo", que serviu para demostrar a aplicação prática de uma técnica ou tecnologia, pois buscava uma maior eficiência, como relatado por David Ricardo em sua obra "Princípios da Economia Política e Tributação” e Karl Marx em “O Capital”.

A Automação (do latim automatus, que significa mover-se por si), por sua vez, guarda intima relação com a tecnologia na medida em que é um sistema automático de controle pelo qual os mecanismos verificam seu próprio funcionamento, efetuando medições e introduzindo correções, sem a necessidade da interferência do homem (FERREIRA, 2010, p. 246).

Holzmann, por sua vez, ao trazer o conceito de automação, observa que a essência da automação é a capacidade de efetuar o processamento de informação sem contato humano:

O termo automação é empregado, atualmente, para definir o processo de inovação tecnológica de base microeletrônica na produção de bens e serviços É com estes significado que se nomeiam, pro exemplo os processos de automação bancária ou automação industrial, traduzindo a utilização da informática nestes setores de atividade. O significado do termo é, no entanto, bem mais amplo. Ele diz respeito a todo instrumento ou objeto que funcione sem a intervenção humana direta, podendo 
ser aplicado a qualquer tipo de máquina ou artefato que opere deste modo (2011, p. 56).

A automação, ganha cada vez mais espaço nos meios produtivos e apesar da preocupação ser antiga, desde o maquinismo, é na atualidade que este preocupação toma vulto pois há o risco de esgotamento do meio ambiente pelo uso abusivo e constante dos recursos naturais, além do risco que desenvolvimento de tecnologias que possam colocar em risco a vida humana como conhecemos hoje. Não é apenas a preocupação do desenvolvimento da fissão nuclear para gerar energia, que também serve como maior ameaça mundial de extermínio da humanidade com a bomba nuclear, mas também o fato do humano ser sistematicamente substituído pela máquina na medida em que é cada vez mais claro a ocorrência da singularidade tecnológica ${ }^{3}$.

Este contexto no qual o ser humano está inserido atualmente teve sua origem e evolução a partir do final do Século XVIII, com a Revolução Industrial ocorrida na Inglaterra, pois foi marco determinante para o nascimento do direito do trabalho e assim houve, pela primeira vez, a substituição da força humana pela máquina a vapor e pelas máquinas têxteis (MARTINS, Sérgio P.; 1999, p.34). Neste mesmo período surge o trabalho assalariado e a utilização da máquina tinha como objetivo único de implementar o aumento da produção e não substituição do homem pela máquina.

Um grande fenômeno social decorrente destas atividades produtivas que utilizavam novas técnicas foi a migração, uma vez que os centros produtivos se localizavam nas cidades, local que os migrantes buscavam ara buscar melhores oportunidades de trabalho, que nem sempre se materializava na medida em que o desemprego era a regra e como alerta Rui Décio Martins sempre haveria alguém disposto a ganhar menos pelo mesmo trabalho: "era a lei da sobrevivência no seu grau mais indigno" e, no tocante tecnologia aplicada na época: "O lado perverso desse progresso é que o trabalhador, agora, não mais possui o conhecimento do início, meio e fim da produção de um bem qualquer, pois a máquina, sendo especializada, impede apropriação desse saber" (2012, p. 228).

\footnotetext{
${ }^{3}$ Singularidade tecnológica é termo criado pelo matemático e escritor Vernor Vinge, é um ponto no futuro a partir do qual as mudanças se darão em tal velocidade que hoje é impossível vislumbrar ou prever o que ocorrerá ou como será o mundo. Segundo Vinge, por volta de 2030 será possível criar um computador com inteligência super-humana que iniciará definitivamente esse processo. Disponível em: <https://www.ibm.com/developerwork s/community/blogs/tlcbr/entry/a_singularidade_tecnologica?lang=en> Acesso em 02/05/2017.
} 
Evidente que este fato não passou desapercebido pelos estudiosos, sofrendo severas críticas de Marx e motivou o mesmo a publicar o primeiro volume de sua principal obra: "O Capital" em 1867. Nesta obra, o autor efetuou uma abordagem sobre o sistema capitalista e aponta estudos sobre o acúmulo de capital e mostra que a classe dos capitalistas fica cada vez mais rica à custa dos operários, que cada vez mais empobrecem. Explica que o homem é estimulado a valorizar o "ter" ao "ser" onde sua vida é medida pelas suas posses e não pelo que ele é. Dessa forma, o trabalho ao invés de realizar o homem, o escraviza; ao invés humanizá-lo, o desumaniza. Para Marx, o trabalhador não é dono de seu trabalho, já que vende a sua força de trabalho para alguém. Dessa forma, o seu trabalho passa a ser algo estranho ao próprio trabalhador (perda da consciência do mesmo) e, ainda, ao produzir um bem que não lhe pertence, o homem propicia para um outro (o empregador), o valor real de sua produção, deixando assim, que esse outro, que nada produziu, se aproprie dele. Na obra “O Capital”, Marx relata sobre a substituição da mão de obra humana pela máquina:

\begin{abstract}
O instrumento de trabalho, ao tomar forma de máquina, logo se torna concorrente do próprio trabalhador. A autoexpansão do capital através da máquina está na razão direta do número de trabalhadores cujas condições de existência ela destrói. Todo o sistema de produção capitalista baseia-se na venda da força de trabalho como mercadoria pelo trabalhador. A divisão manufatureira do trabalho particulariza esta força de trabalho, reduzindo-a a habilidade muito limitada de manejar uma ferramenta de aplicação estritamente especializada. Quando a máquina passa a manejar a ferramenta, o valor de troca de força de trabalho desaparece ao desvanecer seu valor de uso. O trabalhador é posto para fora do mercado como o papel-moeda retirado de circulação. A parte da classe trabalhadora que a maquinaria transforma em população supérflua, não mais imediatamente necessária à autoexpansão do capital, segue uma das pontas de um dilema inarredável: ou sucumbe na luta desigual dos velhos ofícios e das antigas manufaturas contra a produção mecanizada, ou inunda todos os ramos industriais mais acessíveis, abarrotando o mercado de trabalho e fazendo o preço da força de trabalho cair abaixo de seu valor (2014, p. 491-492).
\end{abstract}

Assim, a força do capital que movimenta e traça os rumos da economia começou a modificar radicalmente o cenário até então existente, pois começou o acúmulo de capital de forma desproporcional ao trabalho vendido pelos trabalhadores.

E foram tímidas as medidas estatais de proteção aos trabalhadores com a promulgação de algumas poucas leis de acordo com Sérgio Pinto Martins: Em 1802, a Lei de Peel, na Inglaterra limitava a jornada dos menores nas fábricas a 12 horas diárias; em 1814, na França a lei que proibiu o trabalho de menores de oito anos; em 1863, Bismarck elabora uma série de leis sociais na Alemanha e, em 1886, na Itália são criadas leis trabalhistas de proteção 
a mulher e ao menor (1999, p. 36).

Os avanços tecnológicos passam a ter grande significado social e econômico a partir da Segunda Guerra Mundial, quando os Estados Unidos da América do norte passaram a ser uma nação hegemônica e também a geração de um bloco de países semiperiféricos, parcialmente industrializados como Reino Unido, França, Bélgica, Holanda e Portugal. E, neste contexto, o Brasil foi encaminhado para a industrialização, como observa Pochmann:

\begin{abstract}
O surgimento deste bloco de países semiperiféricos se deu a partir da combinação do forte esforço das elites internas com a oportunidade de ter espaço geográfico nacional transformado pela concorrência das grandes empresas transnacionais, especialmente durante a fase de bipolaridade das relações internacionais. A periferização da indústria ocorreu, em grande medida, sob a liderança do Estado, por meio da expansão e da proteção de mercado interno, o que permitiu a rápida passagem da fase-agrária exportadora para a de desenvolvimento industrial (2012, p. 24).
\end{abstract}

Todavia o padrão de industrialização norte americano no final da década de 1960 encontrava-se esgotado, bem como pela falência do acordo de Bretton Woods ${ }^{4}$. O que motivou esta ruína foi a globalização aliada a tecnologia disponível, como assevera Pochmann:

[...] A globalização financeira, que combina com o desenvolvimento de inovações financeiras, com informatização de mercados, potencializa o volume de transações de curto prazo, pressionando a eliminação de controles cambiais, a liberação das taxas de juros e a desregulamentação bancária (2012, p. 26).

Mas o que definitivamente foi a mola propulsora de desenvolvimento tecnológico no século passado foi a Guerra Fria entre Estados Unidos da América e dos países da União Soviética, onde os governos destes países justificaram pesados investimentos, como o satélite soviético Sputnik, que serviu como marco inicial de uma grande geração de pesquisadores (REICH, 2008, p. 41). O mesmo se pode dizer em relação a criação da Internet, que surgiu da necessidade do Pentágono transmitir informações complexas em tempo real e foi batizada inicialmente como ARPANET pela Agência de Projetos de Pesquisa Avançada do Departamento de Defesa (REICH, 2008, p. 57).

\footnotetext{
${ }^{4}$ Sistema econômico implantado após a Segunda Guerra Mundial destinado a reger a economia internacional principalmente em relação aos países industrializados.
} 
A globalização neste período foi fortemente viabilizada pela utilização de recursos tecnológicos mais avançados. Reich observa que:

O ingrediente crítico que deflagrou a globalização foi o conjunto de novas tecnologias de transporte e de comunicações, a maioria relacionada com o reforço do poderio americano durante a Guerra Fria - navios e aviões de carga, cabos submarinos, contêineres de aço e, por fim, satélites interligando os continentes reduzindo drasticamente o custo da movimentação de mercadoria em qualquer ponto do planeta (2008, p. 60).

Alexandre Agra Belmonte, enumera alguns dos principais efeitos das novas tecnologias nas relações de trabalho:

a) maior produção com menor custo; b) produtos e serviços mais baratos com maior circulação de capital; c) diminuição ou eliminação de fronteiras; d) detenção setorial de tecnologias e de capital; e) diminuição do Poder dos Estados perante empresas transnacionais e multinacionais - tidas como novos atores globais - e, com isso, uma dificuldade de impor regras em benefício do social ante o avanço econômico e técnico desses atores (2007, p. 15).

Mas a movimentação econômica mundial é implacáveis e na década de 1970, que além de sofrer com a crise do petróleo já não aceitava mais o ultrapassado modelo de Henry Ford, conforme aponta Holzmann:

[...] a queda da produtividade e o aumento da resistência operária ao seu aumento; a saturação dos mercados dos países centrais para produtos homogêneos da produção fordista e a diversificação do mercado de consumo; o acirramento da competição pela entrada no mercado de países antes de papel secundário nesse cenário, como Japão e Alemanha (sobretudo na indústria automobilística); e a crise do Estado providência, entre outros (2011, p. 202).

Assim, este modelo foi atualizado pelas técnicas japonesas implantadas na década de 1950 pela busca de maior eficiência na indústria, conhecida como toyotismo ${ }^{5}$, que diferentemente do modelo de Ford (que mantinha estoque e o capital para de circular), ajusta a produção à demanda de mercado, ou seja, somente é produzido o que já foi vendido. (HOLZMANN, 2011, p. 427).

\footnotetext{
5 “Toyotismo designa o modo de organizar os processos de trabalho e de produção, idealizado pelo engenheiro Taiichi Ohno e introduzido na fábrica da Toyota, no Japão, a partir de 1950. Foi amplamente difundido a partir dos anos 1970, constituindo um dos recursos d estratégia capitalista para fazer frente a à crise da produção em massa fordista" (HOLZMANN, 2011, p. 426).
} 
O modelo toyotista absorveu bem a tecnologia na medida em que uma grande característica deste modelo é a flexibilidade no processo produtivo que é aplicada inclusive na maquinaria, não ficando esta limitada a uma única função. Desta forma é possível contar com agilidade na produção ante as constantes inovações bem como as flutuações de mercado, e aduz Holzmann:

[...] A agilidade no atendimento das flutuações do mercado tem sido facilitada pela tecnologia informática, que permite renovação, em curto tempo, de artigos com novas especificações, por meio de programas de computador que armazenam as diversas possibilidades de sua variação. Viabiliza-se em pouco tempo, a produção de pequenos lotes de produtos diversificados, pertencentes à mesma família de peças ou de artigos, por meio de reprogramação das operações das máquinas via computador (2011, p. 428).

Assim, a tecnologia, utilização de técnicas que busquem maior eficiência e automação têm relação direta com o denominado desemprego estrutural, que também pode ser conceituado como desemprego tecnológico:

O desemprego tecnológico refere-se a redução do número de trabalhadores decorrente da aplicação da tecnologia tradicional ou das inovações, na medida em que elas representam racionalização dos processos produtivos e aumento da produtividade de trabalho, sem que haja uma necessária contrapartida em termo de incremento na demanda de trabalho (BASTOS, 2011, p. 105).

O desemprego tecnológico assim ocorrerá quando o posto de trabalho que era originariamente ocupada pelo homem é substituído por máquina, robô ou qualquer outra forma artificial e não humana. O desemprego, por si só, faz parte da economia onde o trabalhador desempregado constitui um exército de reserva ${ }^{6}$, mas a tendência mundial é que o desemprego cresça cada vez mais nas atividades do primeiro setor. Além do desemprego estrutural há outras formas de desemprego, como define Pochmann:

[...] o desemprego aberto, que corresponde aos trabalhadores que procuram ativamente por uma ocupação, estando em condições de exercê-la imediatamente e

\footnotetext{
${ }^{6}$ Singer explica sobre o fenômeno: “[...] As políticas fiscais e monetárias tendem a impedir que a economia se 'aqueça' em demasia, o que na prática implica manter uma generosa margem de sobreoferta de força de trabalho. Neste sentido, o desemprego não é um 'mal' mas um efeito funcional de políticas de estabilização exitosas. Quando a demanda por mercadorias, seja para consumo ou para inversão, é contida, a fim de que os preços não subam, é óbvio que as empresas vendem menos, portanto, produzem menos e ipso facto empregam menos. A concorrência intensificada entre as empresas, obriga-as a reduzir custos e, portanto, a aumentar ao máximo a produtividade do trabalho, o que implica reduzir também ao máximo a compra de força de trabalho. Os desempregados, que outrora eram denominados exército industrial de reserva, desempenham o mesmo papel que mercadorias que sobram nas prateleiras: eles evitam que os salários subam” (2001, p. 13).
} 
sem desenvolver qualquer atividade laboral, indica o grau de concorrência no interior do mercado de trabalho em torno do acesso às vagas existentes. $\mathrm{O}$ subemprego e outras formas de sobrevivência respondem pela parte menos visível do excedente de mão de obra porque envolvem os trabalhadores que fazem "bicos" para sobreviver e também procuram por trabalho, assim como aqueles que deixam de buscar uma colocação por força de um mercado de trabalho extremamente desfavorável (desemprego oculto pelo trabalho precário e pelo desalento) (2012, p. 78).

Uma das formas mais claras de utilização dos meios tecnológicos é a atribuição do serviço ao consumidor, que efetua o trabalho através do autosserviço, como apontado por Stanging:

[...] O autosserviço cresce rapidamente. Os empregos estão sendo terceirizados para os clientes, e as pessoas são instadas a usar sites na internet em vez de canais diretos de comunicação, e terminais de pagamento automático em vez de caixas registradoras operadas por seres humanos. O varejo, os serviços de hotelaria, turismo e restaurantes e as firmas de assistência médica têm gasto bilhões de dólares em tecnologia de autosserviço e o investimento está crescendo $15 \%$ ao ano. A justificativa das empresas é o "prazer da autonomia dos clientes"; na realidade, tratase de uma transformação da tarefa em trabalho (2014, p. 190-191).

Para que as empresas possam manter a competitividade em um cenário de grandes modificações econômicas, foi implementada possibilidade global da deslocalização dos centros de produção, com a transferência das cadeias de produção para países com menor custo. Reich explica que a partir do início da década de 1970 a revolução tecnológica a modificação do sistema de produção, até então monopolista, para inseri-lo em "cadeias de fornecimento mundiais, onde se adicionavam componentes e serviços onde quer que fossem produzidos com mais qualidade e custos baixos" (2008, p. 63) e que forçam, assim, a criação e manutenção da flexibilização:

Flexibilização relativa ao mundo do trabalho é o conjunto de processos e de medidas que visam alterar as regulamentações concernentes ao mercado de trabalho e às relações do trabalho, buscando torna-las menos ordenadas e possibilitando arranjos considerados inovadores diante de uma forte tradição de controle legal das relações laborais. Essa tradição foi sendo construída ao longo do século XX, consolidada como resultado do forte movimento dos trabalhadores e de políticas públicas de bem estar social. A proposta de flexibilização contrapõe-se a esta tradição, que diz respeito às proteções que os trabalhadores obtiveram nas condições de venda e uso de sua força de trabalho e à garantia de direitos a benefícios e serviços decorrentes de sua condição de trabalhadores (HOLZMANN; PICCININI. 2011, p. 196).

Singer defende que a palavra "precarização" do trabalho se amolda melhor que a palavra desemprego em relação ao surgimento dos novos postos de trabalho resultado do 
emprego de meios tecnológicos e da nova divisão internacional do trabalho que tolhem as compensações e garantias das leis e contratos coletivos de trabalho::

[...] Uma única empresa grande necessita muitas vezes dos serviços em tempo completo de uma equipe profissional, seja de contabilidade, de vigilância, de fornecimento de refeições, de seleção de executivos, de pesquisa de mercado, etc. Outrora, a empresa empregava a equipe. Hoje ela prefere que a equipe se constitua em pequena firma independente e lhe preste os serviços. Para a empresa-cliente, a vantagem está na flexibilidade do novo relacionamento e também no menor custo do trabalho, pois ela deixa de pagar o tempo morto, quando a equipe não tem o que fazer, e as horas-extras, quando a urgência da tarefa impõe trabalho além da jornada normal. Os profissionais que passam a trabalhar "por conta própria" ganham a possibilidade (teórica) de atender outros clientes, mas correm o risco que "o" cliente se volte para outro fornecedor. Em suma: o ex-empregador ganha novos graus de liberdade, os ex-empregados perdem a segurança que tinham (2001, p. 24-25).

O trabalho tradicional sofreu inexorável mutação ante as imposições do mercado imposta ocorridas desde a década de 1980 culminando na flexibilização, que foi o motivador lógico para a terceirização e, em decorrência disso o enfraquecimento dos vínculos e obrigações dos empregadores, muitas vezes conquistadas com anos de luta pelos trabalhadores e seus sindicatos. O resultado dessa flexibilização global é a criação de uma classe social desorganizada, que Standing denominou de precariado que "poderia ser descrito como um neologismo que combina o adjetivo 'precário' e o substantivo relacionado 'proletariado"' $(2014$, p. 23$)$ e discorre sobre o tema:

\begin{abstract}
O precariado tem características de classe. Consiste em pessoas que têm relações de confiança mínima com o capital e o Estado, o que as torna completamente diferentes do assalariado. E ela não tem nenhuma das relações de contrato social do proletariado, por meio das quais as garantias de trabalho são fornecidas em troca de subordinação e eventual lealdade, o acordo tácito que serve de base para os Estados de bem-estar social. Sem um poder de barganha baseado em relações de confiança e sem poder usufruir de garantias em troca de subordinação, o precariado é sui generis em termos de classe. Ele também tem uma posição de status peculiar, não se encaixando em alto status profissional ou em atividades artesanais de médio status. Uma forma de explicar isso é dizendo que o precariado tem "status truncado" (2014, p. 25-26).
\end{abstract}

Standing entende que o precariado é constituído pelos trabalhadores que foram despojados das seguintes garantias: garantia de mercado de trabalho, garantia de vínculo empregatício, segurança no emprego, segurança no trabalho, garantia de reprodução de habilidade, segurança de renda, garantia de representação ${ }^{7}(2014$, p, 28).

\footnotetext{
${ }^{7}$ Garantia de mercado de trabalho - oportunidades adequadas de renda- salário; no nível macro, isto é realçado
} 
O trabalhador atual tem grande possibilidade de integrar o precariado através das seguintes modalidades: trabalho a distância, terceirização, trabalho temporário, trabalho de meio período, o trabalho nas centrais de atendimento, estágio, etc.

A tecnologia viabiliza a possibilidade do trabalhador prestar seu serviço à distância, também conhecido como teletrabalho. Este, evidentemente, segue no interesse do "empregador" uma vez que não precisa disponibilizar um espaço físico para o trabalhador, nem se preocupar com os custos de energia elétrica, água e outros custos adicionais de um empreendimento tradicional, e nem como segurança e saúde do meio ambiente do trabalho, aliado ao fato de que não há o contato físico entre os funcionários, inviabilizando que os mesmos possam se reunir para discutir condições de trabalho, enfraquecendo o poder de negociação dos mesmos.

Raramente se fala dos efeitos nefastos desta modalidade de trabalho. Esta "comodidade" que o trabalho a distância hipoteticamente pode trazer com a liberdade de horários pode ser inversamente proporcional a falta do contato com demais colegas de trabalho, pois pode levar o trabalhador a estagnação de seus conhecimentos e ainda lhe tira a oportunidade de reunião com os colegas de trabalho para que se discuta as condições do mesmo e troca de experiências profissionais. Rui Decio Martins ensina sobre o tema:

Um fato interessante neste contexto é que o "novo" trabalhador fará sua tarefa em
casa e não mais precisará se deslocar aos antigos e tradicionais locais de trabalho.
Se, por um lado isso lhe proporciona certa economia de tempo e dinheiro - pois não
gasta com o transporte casa-trabalho-casa-, por outro o coloca numa situação não
rara de isolamento profissional e social. Ao encastelar-se no seu local particular de
trabalho nem sempre vê o mundo passar, pois a falta do contato humano com outros

por um compromisso governamental de "pleno emprego". Garantia de vínculo empregatício - Proteção contra a dispensa arbitrária, regulamentação sobre contratação e demissão, imposição de custos aos empregadores por não aderirem às regras e assim por diante. Segurança no emprego - Capacidade e oportunidade para manter um nicho no emprego, além de barreiras para a diluição de habilidade, e oportunidades de mobilidade "ascendente" em termos de status e renda. Segurança do trabalho - Proteção contra acidentes e doenças no trabalho através, por exemplo, de normas de segurança e saúde, limites de tempo de trabalho, horas insociáveis, trabalho noturno para as mulheres, bem como compensação de contratempos. Garantia de reprodução de habilidade Oportunidade de adquirir habilidades, através de estágios, treinamento de trabalho, e assim por diante, bem como oportunidade de fazer uso dos conhecimentos. Segurança de renda - Garantia de renda adequada e estável, protegida, por exemplo, por meio de mecanismos de salário mínimo, indexação dos salários, previdência social abrangente, tributação progressiva para reduzir a desigualdade e para complementar as baixas rendas. Garantia de representação - Possuir uma voz coletiva no mercado de trabalho por meio, por exemplo, de sindicatos independentes, com o direito de greve (STANDING, 2014, p. 28). 
profissionais de sua área de trabalho e/ou de outros campos do saber profissional e com experiências próprias pode, com o passar do tempo, levar aquele trabalhador a uma fossilização de seus conhecimentos e, com isso, de suas habilidades laborais. Em breve poderá estar fora do mercado de novo (2012, p. 233).

O trabalho terceirizado também é resultado da flexibilização e pode ser conceituado como aquele na qual uma empresa transfere sua atividade-fim para outra empresa com a finalidade de tornar mais flexíveis a organização as relações de trabalho, bem como desenvolver maior especialização de atividades (GARCIA, 2011, p. 423).

O trabalho terceirizado encontra justificativa no fato de diminuir os custos trabalhistas, onde as empresas transferem a produção para locais que tenham custo mais baixo e a possibilidade de ajustes na estrutura de trabalho com o custo mínimo (STANDING, 2014, p. 22).

Em 31 de março de 2017 foi publicada a Lei n ${ }^{0} 13.429$ de 31 de março de 2017 aprovou a possibilidade da terceirização da atividade fim, popularmente conhecida como terceirização ilimitada, demonstrando assim o caráter de flexibilização e consequente enfraquecimento das categorias tradicionais e de seus sindicatos.

A liberação da terceirização sem limites encontra sua razão de ser pela elevação desenfreada do setor terciário, que é o resultado da mutação da sociedade de massa para sociedade de consumo, conforme observa Juliana Duarte:

\footnotetext{
A sociedade do trabalho atravessa talvez, sua pior crise. A concentração no setor terciário traz consigo o fenômeno da terceirização. As empresas passam a descentralizar seu processo produtivo entregando-o a profissionais liberais, médias ou pequenas empresas. Elas não perderam de vista seu "produto final", apenas não arcam mais com a responsabilidade de uma produção concentrada e organizada. $\mathrm{O}$ objetivo é reduzir o número de empregados e os custos de produção, aumentando o lucro, ou seja, a mais-valia (2015, p. 112).
}

A flexibilização traz consequências sociais e Duarte aponta uma delas: "Os trabalhadores que conseguem colocação nas empresas fornecedoras não são tão bem remunerados, trabalham mais, principalmente quando são 'donos' dos negócios, e são pressionados pelo único cliente e pela concorrência" (2015, p. 112).

Singer aponta que as conquistas trabalhistas como a limitação da jornada, 
descanso semanal remunerado e férias, tiveram seu papel para frear o desemprego face ao aumento da produtividade nos anos dourados (1945-1973), agora foram substituídos por ocupações de conta própria onde:

[...] Seus ganhos em geral se pautam não pelo tempo de trabalho dado, mas pelo montante de serviços prestados. Nesta situação, os trabalhadores por conta própria tendem a trabalhar cada vez mais, na ânsia de ganhar o suficiente para sustentar o padrão usual de vida (2001, p. 29).

Outro consequência para o empregado de uma empresa que está passando pelo processo de automatização perde não apenas sua qualidade de vida, mas sua segurança espiritual, a partir do momento que passa a ter medo de se tornar um desempregado. Este fato já foi descrito por Carvalho no que diz respeito a automação no setor automobilístico:

\begin{abstract}
A maior preocupação dos operários, sua grande ansiedade principalmente no momento em que os novos equipamentos começaram a ser instalados esteve relacionada com o medo de perder o emprego (CNRH, 1986: 180). Neste período foi muito forte a boataria a respeito de demissões decorrentes da entrada em operação das máquinas automatizadas. O receio com a redução das oportunidades futuras de trabalho permanece um sentimento marcante $(1987$, p. 205).
\end{abstract}

O trabalho, além de objetivar a subsistência do ser humano, tem destaque no desenvolvimento econômico e social da comunidade em ele está inserido e, ainda, o caráter pessoal que pode ser vislumbrado através da felicidade. Patricia D. F. Diniz aponta sobre o tema:

Sendo o trabalho tão importante para o homem e para a sociedade, seja ele realizado de forma livre ou relativamente livre, respeitando entendimento contrário, pode-se afirmar que ele tende a trazer felicidade ao indivíduo, e a ausência, o ócio e o mero desempenho de outra atividade que não seja considerada trabalho tende a causar a infelicidade no homem, pois é um importante aspecto da vida em sociedade (2015, p. 26).

Estas e outras consequências sociais exigem do Estado uma postura de forma a proteger os direitos sociais, que de fato, não ocorre de forma efetiva. O Estado segue o modelo neoliberal e não faz qualquer ingerência no mercado de forma a prevenir a ocorrência do desemprego tecnológico, atuando somente no momento posterior com políticas sociais pouco efetivas, como o seguro desemprego e políticas sociais de acesso ao emprego, com suporte de qualificação profissional. 
Standing verificou que muitas vezes a qualificação profissional, por si só, além de não resolver o problema do trabalhador acaba por criar outro:

\begin{abstract}
[...] Podem-se passar anos adquirindo qualificações e, em seguida, descobrir que elas se tornaram obsoletas ou insuficientes. Uma aceleração da obsolescência profissional afeta muitos que estão no precariado. Há um paradoxo: quanto mais qualificado o trabalho, maior a probabilidade de haver aperfeiçoamentos que exigem "reciclagem". Em outras palavras: quanto mais treinado você for, maior a probabilidade de que você se torne inábil na sua esfera de competência. Talvez o termo "desqualificado" fosse uma maneira de descrever o que acontece. Isso dá uma estranha dimensão de tempo à ideia de habilidade. Não é apenas um caso de você ser tão bom hoje quanto era ontem, mas de você ser tão bom agora quanto deve ser amanhã. A reação comportamental à insegurança de habilidade pode ser um frenesi de investimento no uso do tempo para o aperfeiçoamento ou pode ser uma paralisia da vontade, uma inatividade decorrente de uma crença de que qualquer curso teria um retorno bastante incerto. Os analistas que exigem sem parar mais treinamento e lamentam a falta de habilidades contribuem apenas para uma crise existencial. Isso não é um clima social favorável ao desenvolvimento de capacidades; é um clima de constante insatisfação e estresse. (2014, p 189).
\end{abstract}

O Estado, assim, não consegue materializar o contido no artigo 23 da Declaração Universal dos Direitos Humanos de $1948^{8}$ :

1. Todo ser humano tem direito ao trabalho, à livre escolha de emprego, a condições justas e favoráveis de trabalho e à proteção contra o desemprego.

2. Todo ser humano, sem qualquer distinção, tem direito a igual remuneração por igual trabalho.

3. Todo ser humano que trabalhe tem direito a uma remuneração justa e satisfatória, que lhe assegure, assim como à sua família, uma existência compatível com a dignidade humana, e a que se acrescentarão, se necessário, outros meios de proteção social.

4. Todo ser humano tem direito a organizar sindicatos e neles ingressar para proteção de seus interesses

Destarte justificada a posição crítica de Joaquín Herrera Flores onde com a citada

Declaração, as pautas mínimas estariam garantidas para uma convivência em harmonia:

[...] temos estas pautas mínimas, que já não necessitam de novas reflexões e que, ademais, são universais. Mas só de olhar a história dos direitos humanos de 1948 para cá, ou seja, se temos presentes os mais de 60 anos de vida da Declaração Universal dos Direitos Humanos, o que vemos, em primeiro lugar, é uma sucessão contínua, às vezes quase sistemática, de violações. E, em segundo lugar percebemos uma conversão dos direitos humanos desde sua qualificação em normas mínimas ou básicas, a partir das quais se construirá universalmente a dignidade, a forma atual de

8 Disponível em: <http://unesdoc.unesco.org/images/0013/001394/139423por.pdf>. Acesso em 07/04/2017. 
compreendê-los como normas máximas ou tetos que não podem ser ultrapassados a menos que enfrentemos toda uma ordem global que tem o poder de castigar os governos de todo o mundo se cometem a atrocidade de serem demasiado fundamentalistas em relação à própria Declaração por todos eles firmada (2009, p. 47-48).

Portanto, não carrega efetividade o simples fato da existência do texto protetivo sem que haja o verdadeiro espírito de universalidade. A universalidade transcende o individualismo onde o ser humano deve ser visto como um membro social merecendo ser incluído no ambiente social, econômico, político e cultural.

A omissão Estatal propicia o aumento de diferenças sociais e limita o acesso ao pleno emprego e distancia cada vez mais a realização da dignidade da pessoa humana, podendo colocar em risco a própria preservação da raça humana.

A Constituição Federal de 1988, por sua vez, trouxe um rol de direitos sociais previstos no Capítulo II e especificamente o artigo $7^{\circ}$ inciso XXVII, que assim dispõe:

\footnotetext{
Artigo $7^{\circ}$ - São direitos dos trabalhadores urbanos e rurais, além de outros que visem à melhoria de sua condição social:

$\cdots$

XXVII - proteção em face da automação, na forma da lei; ..".
}

Verifica-se que o dispositivo busca coibir o abuso e o desequilíbrio social, de forma a não substituir o trabalhador por máquina. Do dispositivo depreende-se também a exigência de lei que regulamente esta proteção, que não foi editada até a presente data. A aplicabilidade desta norma, para José Afonso da Silva, é limitada, uma vez que não produzem todos os seus efeitos essenciais haja vista que não há o conteúdo normativo completo cabendo esta matéria ao legislador ordinário ou órgão Estatal (2012, p. 82).

Nesta classificação da norma constitucional prevista no artigo $7^{\circ}$, inciso XXVII, ao mencionar "na forma da lei", indica que esta norma constitucional, quanto a sua eficácia, é limitada e tendo em vista seu conteúdo social converge para uma norma programática. Silva entende que esta norma específica tem conteúdo programático vinculado ao princípio da legalidade, ou seja, dependerá de lei para que atinja sua finalidade: 
[...] a lei é que tem que procurar a forma de proteção; aqui a norma já aponta um beneficiário mais direto: os trabalhadores, destinatários da proteção prometida; a programaticidade da norma é clara, enquanto a lei é que tem que criar programas específicos para proteger os trabalhadores em face da automação (2012, p. 145).

Numa visão ortodoxa, o dispositivo constitucional seria inaplicável ante a ausência da legislação regulamentadora, a norma seria inócua. Entretanto, o espírito buscado do legislador constitucional foi de conceder efetiva proteção ao trabalhador, razão pela qual este dispositivo deve ser analisado sob vários aspectos, da interpretação literal até a análise sistemática com os demais dispositivos constitucionais.

Tradicionalmente os direitos sociais estão previstos na segunda dimensão dos direitos fundamentais e, assim, demandam a atuação estatal para realização da justiça social. Sobre o tema, Sarlet explicita: "Não se cuida mais, portanto, de liberdade do e perante o Estado, e sim de liberdade por intermédio do Estado". O autor enfatiza ainda que estes direitos de segunda dimensão buscam a realização justiça social, mas não se limita a isto, pois correspondem às reivindicações das classes menos favorecidas (2015, p. 47-48).

A industrialização e a aplicação das novas tecnologias foram e são fundamentais para o desenvolvimento econômico, mas também trazem as desigualdades sociais diante da acumulação de capital desproporciona entre aquele que vendo sua mão de obra (trabalhador) e o detentor dos meios produtivos. Assim, é importante verificar que na maioria esmagadora das vezes, a tecnologia está a serviço da minoria acumuladora de capital, que possui o controle e aplicação das tecnologias.

Assim, a classe menos favorecida (precariado), passa a ser ainda menos favorecida pela supressão contínua dos direitos que foram conquistados com muita luta, sofrimento e infelicidade dos trabalhadores, justificando a existência não apenas dos direitos de segunda geração, mas também as liberdades sociais como o direito de greve e liberdade de sindicalização.

Evidente que com a flexibilização de direitos, as liberdades tendem a se tornar inócuas uma vez que os sindicatos já vêm sendo esvaziados em suas categorias tradicionais com a pulverização dos trabalhadores em setores terciários da economia. Assim, este parece 
ser um fato irreversível, razão pela qual o intérprete do texto constitucional deve se esmerar na maior amplitude possível da preservação dos direitos sociais, sob pena de serem abolidos.

Assim, a interpretação inicial deve ser a semântica. Extrai-se do comando constitucional que uma das partes é o trabalhador e a outra, da qual se cobra a proteção estatal é a sociedade. E qual a proteção que o dispositivo constitucional se refere? A proteção é a limitação da utilização dos meios tecnológicos ${ }^{9}$, seja no que diz respeito a condição social do trabalhador, seja em relação ao meio ambiente de trabalho.

Assim, a "automação" referida no texto constitucional não pode ter a interpretação exclusivamente técnico-científica como mencionado anteriormente, mas a interpretação deve ser feita da forma mais ampla possível, no sentido de que toda e qualquer técnica, sistema ou máquina que tenha o caráter de substituir a mão de obra humana.

Outra interpretação necessária é a teleológica, onde de deve buscar o verdadeiro espírito do dispositivo constitucional, a preocupação traçada pelo legislador constitucional. Ainda que seja impossível prever todas as formas de avanços tecnológicos, ao editar a norma do artigo $7^{\circ}$, inciso XXVII, há o reconhecimento da existência da mão de obra artificial e o poder da mesma em substituir a mão de obra humana.

A interpretação sistemática não deixa dúvidas do objetivo pretendido no dispositivo em discussão. Da análise deste com artigo $1^{\circ}$, inciso III (que objetiva a dignidade da pessoa humana) com o artigo $6^{\circ}$ (que assegura a todo o brasileiro o direito ao trabalho) e, também, com o artigo 170 caput (valorização do trabalho humano) e artigo 170, inciso VIII (assegura a busca do pleno emprego) resta claro que o Estado tem o dever de atuar e criar limitações aos particulares de forma a garantir a viabilidade de todos estes direitos.

Portanto, ainda que o dispositivo constitucional previsto no artigo $7^{\circ}$, inciso XXVII não tenha sido regulamentado é perfeitamente possível a provocação do Poder Judiciário a fim de que o mesmo aprecie a lesão do direito do trabalhador, e os efeitos da

\footnotetext{
${ }^{9}$ Marx descreveu a situação do início da Revolução Industrial, onde a máquinas permitiam o emprego de trabalhadores sem força muscular, mas com membros flexíveis e, assim, viabilizada a exploração do trabalho das mulheres e crianças e, como consequência, barateando o custo da força de trabalho (2014, p. 451).
} 
decisão poderão depender do instrumento utilizado pela parte autora ou da corrente adotada pelo órgão julgador. Assim merecem ser citados dois julgamentos que abordaram o tema em debate:

PROTEÇÃO EM FACE DE AUTOMAÇÃO - SISTEMA DE MONOCONDUÇÃO - PROIBIÇÃO - Por incrementar o risco de acidentes ferroviários, o sistema de monocondução das locomotivas deve ser proibido. Não se ignoram os benefícios da evolução tecnológica, nem se quer que esta seja paralisada. Todavia, esta deve ter como finalidade a melhoria da condição social do trabalhador, e não a pura extinção de postos de trabalho. Ademais, deve-se evitar que a tecnologia, no afã de reduzir custos, acabe por aumentar o risco à saúde do trabalhador. TRT-RJ. RO $\mathrm{n}^{\circ}$ 2236004720025010421, Terceira Turma, Rel. Des. Giselle Bondim Lopes Ribeiro. j. 09/07/2012 pub. 13/07/2012.

Ementa: CONSTITUCIONAL. MANDADO DE SEGURANÇA. PROIBIÇÃO DE AUTOATENDIMENTO EM POSTOS DE COMBUSTÍVEIS. CLÁUSULA INSERTA EM CONVENÇÃO COLETIVA DE TRABALHO. VALIDADE. PROTEÇÃO DO TRABALHO EM FACE DA AUTOMAÇÃO. 1. Cláusula inserta em Convenção Coletiva de Trabalho, que proíbe o sistema de auto-atendimento em postos de combustíveis, não importa violação ao art. 238 da Constituição Federal, pois enquanto este diz respeito à relação jurídica contratual que vincula comprador e vendedor, aquela trata de questão atinente à relação de emprego (patrão $\mathrm{X}$ empregado). 2. À míngua de lei (em sentido formal) existente no ordenamento jurídico dispondo em sentido contrário, é válida, como se lei fosse, convenção coletiva de trabalho que, livremente pactuada entre os sindicatos signatários, proíbe o sistema de auto-atendimento em postos de combustíveis, assim realizando o princípio da proteção do trabalho em face da automação, na forma do art. XXVII, da CF (Apelação em Mandado de Segurança n ${ }^{\circ}$ AMS 5154 RS 1999.71.07.005154-9, TRF 4a Região, Terceira Turma. Re. Des. FRANCISCO DONIZETE GOMES; jul. 24/09/2002, pub. DJ 09/10/2002 PÁGINA: 754).

Em ambos os casos acima foram efetuadas a análise específica de proteção do posto de trabalho face a supressão do mesmo pelo uso da automação e também a possibilidade da implementação ao autoatendimento viabilizado pela aplicação de meios tecnológicos. Em ambos os casos os efeitos da decisão ficarão limitados ao caso concreto, não externando para outros casos e categorias.

Outra forma de possibilidade para que a norma constitucional seja regulamentada é o Mandado de Injunção, que encontra fundamento no artigo $5^{\circ}$, LXXI da Constituição Federal ${ }^{10}$ e, assim, já teve a Corte Suprema a possibilidade de analisar um caso quando do julgamento do Mandado de Injunção ${ }^{\circ}$ 618-MG ${ }^{11}$ :

\footnotetext{
10 "conceder-se-á, mandado de injunção sempre que a norma regulamentadora torne inviável o exercício dos direitos e liberdades constitucionais e das prerrogativas inerentes à nacionalidade, à soberania e à cidadania".
} 
MANDADO DE INJUNÇÃO. CONSTITUCIONAL E TRABALHISTA. ALEGADA AUSÊNCIA DE NORMA REGULAMENTADORA DO ART. $7^{\circ}$, INCS. XXI E XXVII, DA CONSTITUIÇÃO DA REPÚBLICA. PROTEÇÃO CONTRA A AUTOMAÇÃO: NÃO DEMONSTRAÇÃO DA INVIABILIDADE DO EXERCÍCIO DO DIREITO CONSTITUCIONAL. AVISO PRÉVIO PROPORCIONAL AO TEMPO DE SERVIÇO: APLICAÇÃO DA LEI N. 12.506/2011. PRECEDENTES. MANDADO DE INJUNÇÃO PARCIALMENTE CONHECIDO, NA PARTE CONHECIDA, PARCIALMENTE CONCEDIDO (Rel. Min. Carmen Lucia, jul. 29/09/2014 pub. 02/10/2014).

O impetrante fundamento o pedido com base no fato de que o mesmo perdeu o posto de trabalho em virtude da automação bancária. O banco empregador, por sua vez, apresentou a seguinte justificativa:

\footnotetext{
"A Coord. de Proces. Serv. Agencias / CPSA DIVINOPOLIS, comunica a rescisão de seu contrato de trabalho com o Banco BEMGE S.A., a partir de 04/12/1998 pelos seguintes motivos:

a) Ajuste do quadro funcional em virtude do aumento de competitividade no segmento financeiro, queda do volume de negócios, e estabilização da economia; b) Inovações tecnológicas e racionalização de métodos e rotinas de trabalho.

Registra-se.

Belo Horizonte, 2 de dezembro de 1998".
}

A Ministra Carmen Lúcia proferiu decisão monocrática onde não conheceu o Mandado de Injunção no tocante ao artigo $7^{\circ}$, inciso XXVII C.F. e fundamentou no sentido de que proteção se dá apenas "em face da automação" e não contra as "inovações tecnológicas", sendo que esta não necessariamente substitui o homem pela máquina. Assim, lamentavelmente o Supremo Tribunal Federal deu interpretação restritiva na medida em que confere tratamentos distintos entre aplicação dos meios tecnológicos e automação.

Assim, a omissão legislativa do dispositivo constitucional contida no inciso XXVII do artigo $7^{\circ}$ da C.F. não inviabiliza a aplicação da proteção constitucional e desloca ao Poder Judiciário o dever de analisar e, se for o caso, integrar a norma incompleta.

\section{CONSIDERAÇÕES FINAIS}

Disponível em: 〈http://www.planalto.gov.br/ccivil_03/constituicao/constituicao.htm〉. Acesso em 09 de junho de 2016.

${ }^{11}$ Disponível em: < http://www.stf.jus.br/portal/jurisprudencia/listarJurisprudencia.asp?s1=\%28\%28618\%2ENU ME $\% 2 \mathrm{E}+\mathrm{OU}+618 \% 2 \mathrm{EDMS} \% 2 \mathrm{E} \% 29 \% 28 \% 28 \mathrm{C} \% \mathrm{C} 1 \mathrm{RMEN}+\mathrm{L} \% \mathrm{DACIA} \% 29 \% 2 \mathrm{ENOR} \% 2 \mathrm{E}+\mathrm{OU}+\% 28 \mathrm{C} \% \mathrm{C} 1$ RMEN+L\%DACIA\%29\%2ENPRO \%2E+OU+\% 28C\%C1RMEN+L\%DACIA\%2\%2EDMS\%2E\%29\%29+NA $\mathrm{O}+\mathrm{S} \% 2 \mathrm{EPRES} \% 2 \mathrm{E} \&$ base=baseMonocraticas\&url=http://tinyurl.com/mo5mtds $>$. Acesso em 08/04/2017. 
A proteção do trabalhador vem se tornando cada vez mais difícil na medida em que a dinâmica da economia muda os contextos sociais e não respeita direitos conquistados com dificuldade pela sociedade.

Os avanços tecnológicos jamais serão freados, mas o que de fato preocupa é que estes avanços estão quase sempre em prol dos acumuladores de capital. Atualmente, somente os grandes empresários, banqueiros e pouquíssimos setores têm a possibilidade de criar ou financiar o desenvolvimento de técnicas, tecnologias e modos de automação que tenham o condão de reduzir drasticamente os custos com mão de obra humana e, assim, empurrar o ser humano para a precarização.

O que há 30 anos era visto como ficção, a substituição do homem pela máquina é hoje uma triste realidade e parece implacavelmente irremediável. A exemplo disso temos a máquina Watson desenvolvida pela IBM, um computador com capacidade cognitiva como relatado por Demartini ${ }^{12}$, que converge para a ocorrência da singularidade tecnológica.

Ainda que seja pouco provável a dominação dos homens pelas máquinas, é certo que os problemas sociais se agravarão de sobremaneira e com um potencial muito maior que o descrito por Marx experimentado pelos operários das tecelagens, haja vista que quase todos os setores da economia são potencialmente atingíveis pelo desemprego tecnológico.

Os acontecimentos e decisões políticas recentes demonstram que os governantes pretendem colocar o país em igualdade de competição com países que já contam com direitos precarizados, como a Índia e China, cedendo assim, às forças do mercado e vilipendiando os direitos conquistados com sacrifícios de lutas, angústias, tristezas da sociedade, tal qual a "lei da terceirização ilimitada" recentemente publicada.

\section{REFERÊNCIAS:}

\footnotetext{
12 DEMARTINI, Mariana. Supercomputador da IBM será atendente do Bradesco em 2016. Disponível em: <http://exame.abril.com.br/tecnologia/supercomputador-da-ibm-sera-atendente-do-bradesco-em-2016/>. Acesso em 23 de março de 2017.
} 
BAUMGARTEN, Maíra; HOLZMANN, Lorena. Tecnologia. In CATTANI, Antonio David; HOLZMANN, Lorena. (Org.). Dicionário de Trabalho e Tecnologia. $2^{\mathrm{a}}$ ed., Porto Alegre: Zouk, 2011.

BELMONTE, Alexandre Agra. Problemas jurídicos do teletrabalho. Revista de Direito do Trabalho, ano 33, n 127, jul/set. São Paulo: RT. 2007.

BRASIL. Constituição $\quad$ Federal (1988). Disponível em <http://www.planalto.gov.br/ccivil_03/constituicao/constituicao.htm>. Acesso em 09 de junho de 2016.

Lei Federal $n^{0}$ 13.429, de 31 de março de 2017. DF, Congresso Nacional, 2017. Disponível em <http://www.planalto.gov.br>. Acesso em 09 de abril de 2017).

CARVALHO, Ruy de Quadros. Tecnologia e Trabalho Industrial: as implicações sociais da automação microeletrônica na indústria automobilística. $1^{\mathrm{a}}$ ed., Porto Alegre: L\&PM, 1987.

DEMARTINI, Mariana. Supercomputador da IBM será atendente do Bradesco em 2016. Disponível em: <http://exame.abril.com.br/tecnologia/supercomputador-da-ibm-seraatendente-do-bradesco-em-2016/>. Acesso em 23 de março de 2017.

DINIZ, Patrícia Dittrich Ferreira. Trabalhador versus Automação, Curitiba: Juruá, 2015.

DUARTE, Juliana. Teoria Jus-Humanista Multidimensional do Trabalho sob a perspectiva do Capitalismo Humanista. Rio de Janeiro: Lumen Juris. 2015.

ELlUL, Jacques. A técnica e o desafio do século. Rio de Janeiro: Paz e Terra. 1968.

FERREIRA, Aurélio Buarque de Holanda. Dicionário Aurélio da língua portuguesa. $5^{\mathrm{a}}$ ed., Curitiba: Positivo. 2010.

FLORES, Joaquin Herrera. Teoria Crítica dos Direitos Humanos: Os Direitos Humanos como Produtos Culturais. Rio de Janeiro: Lumens Juris. 2009.

GARCIA, Sandro Ruduit. Terceirização. In CATTANI, Antonio David; HOLZMANN, Lorena. Dicionário de Trabalho e Tecnologia. $2^{\text {a }}$ ed., Porto Alegre: Zouk, 2011.

HOLZMANN, Lorena. Fordismo. Toytismo. In CATTANI, Antonio David; HOLZMANN, Lorena. Dicionário de Trabalho e Tecnologia. $2^{\mathrm{a}}$ ed., Porto Alegre: Zouk, 2011.

HOLZMANN, Lorena; PICCININI, Valmíria. Flexibilização. In CATTANI, Antonio David; HOLZMANN, Lorena. Dicionário de Trabalho e Tecnologia. $2^{\mathrm{a}}$ ed., Porto Alegre: Zouk, 2011.

MARTINS, Rui Decio. A Técnica e o Teletrabalho. Violação dos Direitos Fundamentais? In: KIM, Richard Pae; et al (Coord.) Direitos Fundamentais Coletivos e Difusos: Questões sobre a Fundamentalidade. São Paulo: Verbatim, 2012. 
MARTINS, Sérgio Pinto. Direito do Trabalho. 9a . ed., São Paulo: Atlas, 1999.

MARX, Karl. O Capital: crítica da economia política. Livro I. Tradução de Reginaldo Sant'Anna. 33 ${ }^{\mathrm{a}}$ ed., Rio de Janeiro: Civilização Brasileira, 2014.

POCHMANN, Marcio. O Emprego na Globalização: A nova divisão internacional do trabalho e os caminhos que o Brasil escolheu. São Paulo: Boitempo. 2012.

REICH, Robert. Supercapitalismo. Trad. Afonso Celso da Cunha Serra. Rio de Janeiro: Elsevier. 2008.

RICARDO, David. Princípios da Economia Política e Tributação. São Paulo: Nova Cultural. 1996.

SARLET, Ingo Wolfgang. A Eficácia dos Direitos Fundamentais, $12^{\mathrm{a}}$ ed., Porto Alegre: Livraria do Advogado, 2015.

SILVA, José Afonso da. Curso de Direito Constitucional Positivo. 19 a ed., São Paulo: Malheiros, 2001.

SINGER, Paul. Globalização e Desemprego: Diagnóstico e Alternativas, $4^{\mathrm{a}}$ ed., São Paulo: Contexto, 2001.

STANDING, Guy. O Precariado: a nova classe perigosa. Trad. Cristina Antunes. Belo Horizonte: Autêntica Editora. 2014. 